\title{
LEVERAGING CITIZEN SCIENCE TO ADVANCE INTERACTIVE SPATIAL DECISION SUPPORT TECHNOLOGY: A SWOT ANALYSIS
}

\author{
R. Shrestha ${ }^{1, *}$, J. Flacke ${ }^{2}$ \\ ${ }^{1}$ NEST Pvt. Ltd, Kathmandu, Nepal - shrestharehana@hotmail.com \\ ${ }^{2}$ Dept. of Urban and Regional Planning and Geoinformation Management, Faculty of Geoinformation Science and Earth \\ Observation, University of Twente, Enschede, the Netherlands - j.flacke@utwente.nl
}

Commission V, WG V/7 \& Commission IV, WG, IV/6

KEY WORDS: Spatial Decision Support System, Planning Support System citizen science, participation, SWOT

\begin{abstract}
:
Over three decades, the Spatial Decision Support System (SDSS) concept has evolved significantly exploiting information technology to assist decision maker in a variety of fields of research, development, and practice. With the communicative turn in planning, which emphasizes public participation in all levels of planning and decision making, these technologies have further matured to support participatory planning by means of supporting diverse stakeholders in the decision making process. However, for multiple reasons, SDSS are still in the domain of expert, largely failing to incorporate general citizens in its use and applications. On the same note, citizen science as a method of inquiry is gaining much attention in recent years to engage general citizens in the scientific research, thereby also empowering them to participate in the decisions of the issues affecting the m. As such, it seems likely that citizen science shows great promise for advancing SDSS for achieving broad citizen engagement in planning and decision-making. This paper discusses the strengths, weaknesses, opportunities, threats (SWOT) of integrating citizen science with SDSS by analyzing existing literature on SDSS and citizen science. In particular, we explore the integration of aspects of citizen science in Interactive Planning Support System (PSS), as one form of SDSS to support wider citizen engagement.
\end{abstract}

\section{BACKGROUND}

Many types of challenging problems faced by decision makers have a geographic or spatial component. Geographical information systems are often used for capturing, storing, manipulating, analyzing and displaying of spatial data implying that geographic information systems implicitly are designed to support spatial decision-making. For many spatial problems, however, geographic information systems do not support decision-making effectively: analytical modelling capabilities are lacking and system designs are not flexible enough to accommodate the process of spatial decision-making (Densham \& Goodchild, 1989). As such, there is an increasing interest in the development of computer based Spatial Decision Support System (SDSS), which is defined as "integrated computer systems that support decision makers in addressing semi-structured or unstructured spatial problems in an interactive and iterative way with functionality for handling spatial and non-spatial databases, analytical modelling capabilities, decision support utilities such as scenario analysis, and effective data and information presentation utilities" (Sugumaran \& Degroote, 2010, p.37).

Over the decades the Spatial Decision Support System (SDSS) concept has matured significantly exploiting information technology to assist decision maker in a variety of fields of research, development, and practice. Literatures on SDSS show that advancement in technology had been fundamental in its evolution (Keenan \& Jankowski, 2019). SDSS once utilized limited database, modeling, and user interface functionality, but technological innovations have enabled more powerful SDSS functionality.

With the communicative turn in planning theory, which is driven by interactive and interpretive process involving a dialogue between stakeholders (Healey, 1996), public participation is being considered as one of the important aspects in all levels of planning and decision making process. Politicians and planning theorists such as Walsch (1997), Forrester (1993), and Burke (1979) stress the need for public participation by explaining that the complex problems of planning require the widest possible range of input (AlKodmany, 2001). Following this paradigm SDSS technologies have further evolved from individual support to collaborative group support in spatial decision making, including different approaches and frameworks such as Collaborative SDSS (Jankowski et al., 1997; Jankowski et al., 2006) , Group Support Systems (Turoff et al., 1993), and Planning Support Systems (Brail \& Klosterman, 2001; Geertman \& Stillwell, 2012; Klosterman, 1997).

\subsection{Interactive Planning Support System}

Of specific application of Planning Support System (PSS), is the development of so-called interactive PSS. An interactive PSS is hardware solutions in the form of digital table combined with geospatial mapping tools specifically dedicated to support group processes (Pelzer et al., 2014). Typically, an application of interactive PSS consists of interactive PSS tools and interactive PSS processes (Flacke et al., 2019). Interactive PSS tool usually consists of large-scale horizontal, touch enabled screen such as MapTable, which allows stakeholders to stand around the table, and a suite of geospatial tool or GIS software

\footnotetext{
* Corresponding author
} 
for map-based interaction (Figure 1). In the present scenario, most of the interactive PSS tools usually make use of standard GIS software products such as ArcGIS, together with suitable extensions such as CommunityViz Scenario 360 (CommunityViz Scenario 360), adding dynamic capability on the tools. Interactive PSS processes, in its current form, usually consists of stakeholder workshops, either in the form of labbased type of controlled experiments as in (Arciniegas et al., 2013; Döweling et al., 2016) or with stakeholders from the real world on the topic that is realistic (Flacke \& De Boer, 2017; Pelzer et al., 2013; Shrestha et al., 2017).

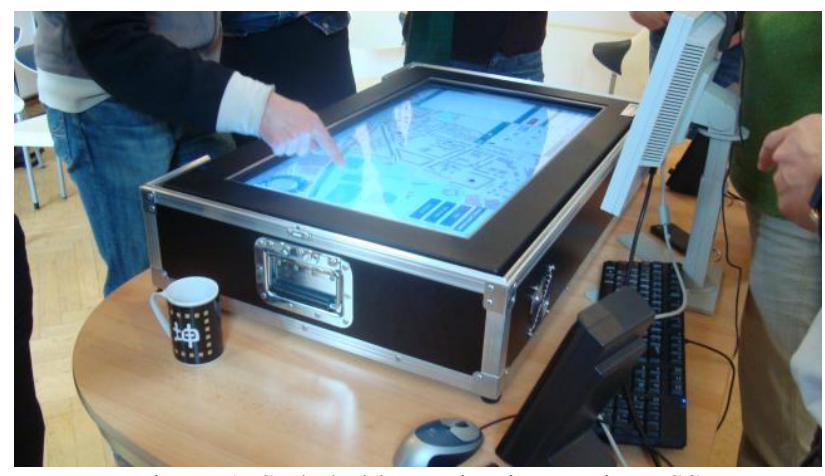

Figure 1. Stakeholders using interactive PSS

The applications of interactive PSS are particularly tailored to support collaborative planning and mainly aims at increasing collaboration and participation of stakeholders while supporting complex planning tasks. Since more than one decade, interactive PSS are increasingly being developed and applied in various case studies related to urban planning (Pelzer et al., 2013), environmental health (Shrestha et al., 2017), energy planning (Flacke \& De Boer, 2017). Research on application of interactive PSS shows that these technologies provide shared map interface to facilitate stakeholder engagement for discussing spatial problems, evaluating alternatives. The user friendly and dynamic interface and processes are argued to support exchange of knowledge and preferences between stakeholders (Flacke \& De Boer, 2017), social learning (Shrestha et al., 2017), as well as contributing to higher quality plans (Pelzer et al., 2014).

Despite the many promising characteristics of interactive PSS for collaborative planning, the application of these interactive PSS are, however, often limited with few number of so-called experts discussing around the interactive PSS, excluding the involvement of broad citizen in its usage and applications. Even with respect to PSS usage by professionals in practice, research on so-called implementation gap of PSS shows that, these tools are being used in limited extent in practice (te Brömmelstroet, 2017; Vonk et al., 2005). Multiple reasons have been detected in its less uptake for facilitating stakeholder engagement with the interactive PSS, such as limited involvement of users in its development (Vonk \& Ligtenberg, 2010), mismatch between the tool and task to be supported, less user-friendliness, lack of experience and intention among practitioners to use the PSS tools (Vonk et al., 2005).

\subsection{Citizen science as a method of inquiry}

A separate field of citizen science is developing as a method of inquiry to involve general citizens, and other relevant stakeholders in scientific activities. A citizen scientist is a volunteer who collects and/or processes data as a part of scientific enquiry (Silvertown, 2009). It is a form of research collaboration involving members of the public in scientific research projects to address real-world problems (Cohn, 2008).

Citizen science emerged with the aim of voluntarily engage people to collect, categorize, transcribe or analyze scientific data to advance scientific knowledge. It is generally related to long-standing programs employing volunteer monitoring, and is often employed as a form of informal science education or outreach to promote public understanding of science (Brossard et al., 2005). Nevertheless, claims on benefits of citizen science activities show that citizen science activities are capable of cultivating behavior change, bringing awareness of the problems, stimulating transformative action and ultimately empowering them to participate in the decisions of the issues affecting them (Kimura \& Kinchy, 2016).

Active engagement in scientific work differentiates citizen science from other forms of public participation in scientific research where volunteers take less active roles (Wiggins \& Crowston, 2011). Most crucially, citizen science can also lead to the development of critical awareness of why social and political change is needed, and how it can be achieved. It is this active nature which separates citizen science from processes of consultation and other forms of civic participation. As such citizen science typologies to date have focused primarily on the integration of public participation in different steps of science research in the form of contributory, collaborative or co-created (Bonney et al., 2009).

Currently, this field is evolving quickly mobilizing people's involvement in information development, social action and justice, and large-scale information gathering on various issues such as environmental monitoring, ecological monitoring, conservation management etc (Conrad \& Hilchey, 2011). An increasing number and variety of citizen science projects are taking advantage of affordances of technology. New technologies such as mobile applications, wireless sensor networks, online gaming are showing great promise in citizen science activities to engage broad audiences (Clery, 2011), motivate volunteers (Sîrbu et al., 2015), improve data collection (Willett et al., 2010), corroborate model results (Snik et al., 2012; Van Brussel \& Huyse, 2019), as well as increase the speed with which decisions can be made (Danielsen et al., 2010).

\section{OBJECTIVE}

Against this background, it seems likely that the development in citizen science activities provide valuable lessons to drive the development of interactive PSS towards broader engagement of citizens. However, to determine what aspects of citizen science can be integrated to drive interactive PSS towards citizen engagement, requires detail analysis on the strength, weakness, opportunities and threats of integrating citizen science aspects with interactive PSS. In this paper, we study the current research and applications of interactive PSS and citizen science activities regarding three aspects -forms of research, formats of engagement and technological development and present the SWOT analysis. 


\section{DATA AND METHODS}

The research is exploratory, and is based on the literature study on interactive PSS cases and citizen science projects. These literatures consist of the most relevant papers, studies and applications on interactive PSS and citizen science projects. We analyzed and structured the main issues regarding the citizen science activities and interactive PSS on three aspects: forms of research, formats of participant engagement and technological development. We then conducted SWOT analysis on each aspects for the interactive PSS.

\section{RESULT AND DISCUSSION}

After analyzing literatures on both interactive PSS and citizen science activities, following Strength, Weakness, Opportunities and Threat can be identified against three aspects-forms of research, formats of participant engagement and technological development - that could potentially be considered as lessons to advance interactive PSS for broad citizen engagement as presented in Table 1.

\begin{tabular}{|c|c|c|}
\hline Aspects & Strengths & Weakness \\
\hline $\begin{array}{l}\text { Forms of research } \\
\text { (community } \\
\text { involvement at a } \\
\text { core) }\end{array}$ & $\begin{array}{l}\text { - Community } \\
\text { issues at its } \\
\text { core } \\
\text { - Greater } \\
\text { acceptance of } \\
\text { PSS usage by } \\
\text { the general } \\
\text { citizen }\end{array}$ & $\begin{array}{l}\text { Motivation } \\
\text { and } \\
\text { willingness to } \\
\text { adopt PSS } \\
\text { tools is } \\
\text { needed to be } \\
\text { harvested }\end{array}$ \\
\hline $\begin{array}{l}\text { Formats of } \\
\text { participants' } \\
\text { engagement } \\
\text { (hackerspace, } \\
\text { maker space, } \\
\text { living labs, } \\
\text { gaming) }\end{array}$ & $\begin{array}{l}\text { Requirements } \\
\text { in the design of } \\
\text { the PSS tools } \\
\text { can be } \\
\text { identified } \\
\text { - Create sense of } \\
\text { ownership } \\
\text { - Task- } \\
\text { technology fit }\end{array}$ & $\begin{array}{l}\text { Resource and } \\
\text { time } \\
\text { intensive in } \\
\text { the form of } \\
\text { training, } \\
\text { logistics, } \\
\text { and/or } \\
\text { experience }\end{array}$ \\
\hline $\begin{array}{l}\text { Technologies } \\
\text { (open source, } \\
\text { mobile apps, } \\
\text { online web- } \\
\text { platform) }\end{array}$ & $\begin{array}{l}\text { Open access, } \\
\text { open source } \\
\text { may reduce } \\
\text { barriers related } \\
\text { to off-the-shelf } \\
\text { software use in } \\
\text { PSS } \\
\text { By leveraging } \\
\text { mobile apps, } \\
\text { web-based } \\
\text { platform, PSS } \\
\text { could evolve } \\
\text { from same- } \\
\text { time-same- } \\
\text { place to } \\
\text { different-time- } \\
\text { different-place }\end{array}$ & $\begin{array}{ll}\text { - Integration } \\
\text { with existing } \\
\text { system } \\
\text { architecture } \\
\text { of PSS } \\
\text { - Privacy } \\
\text { protection } \\
\text { - Data quality } \\
\text { control }\end{array}$ \\
\hline
\end{tabular}

\begin{tabular}{|l|ll|l|}
\hline Categories & \multicolumn{2}{|l|}{ Opportunities } & Threat \\
\hline $\begin{array}{l}\text { Forms of } \\
\text { research } \\
\text { (community } \\
\begin{array}{l}\text { involvement at a } \\
\text { core) }\end{array}\end{array}$ & $\bullet \begin{array}{l}\text { Helps to forge } \\
\text { partnership } \\
\text { Building } \\
\text { communities of }\end{array}$ & $\bullet \begin{array}{l}\text { Resource and } \\
\text { time } \\
\text { intensive }\end{array}$ \\
\hline
\end{tabular}

\begin{tabular}{|c|c|c|}
\hline Categories & Opportunities & Threat \\
\hline & practice & \\
\hline $\begin{array}{l}\text { Formats of } \\
\text { participants' } \\
\text { engagement } \\
\text { (hackerspace, } \\
\text { maker space, } \\
\text { living labs, } \\
\text { gaming) }\end{array}$ & $\begin{array}{l}\text { Design of more } \\
\text { user friendly } \\
\text { PSS tools }\end{array}$ & $\begin{array}{l}\text { - Simplicity } \\
\text { over } \\
\text { complexity of } \\
\text { real world } \\
\text { problems }\end{array}$ \\
\hline $\begin{array}{l}\text { Technologies } \\
\text { (open source, } \\
\text { mobile apps, } \\
\text { online web- } \\
\text { platform }\end{array}$ & 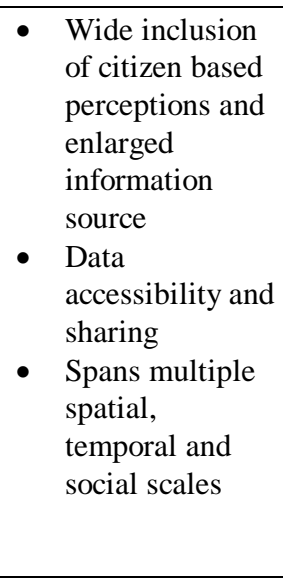 & $\begin{array}{ll}\text { - } & \text { Large users } \\
\text { and data } \\
\text { submission } \\
\text { don't lead to } \\
\text { active } \\
\text { participation } \\
\text { - Social } \\
\text { learning/ } \\
\text { decision } \\
\text { making } \\
\text { depersonaliza } \\
\text { tion } \\
\text { Loss of face- } \\
\text { to-face } \\
\text { interaction }\end{array}$ \\
\hline
\end{tabular}

Table 1. SWOT on each aspects

\subsection{Forms of research}

Citizen science projects show that citizen science activities include both community based monitoring, "a process where concerned citizens, government agencies, industry, academia, community groups, and local institutions collaborate to monitor, track and respond to issues of common community concern" (Whitelaw et al., 2003) and/or community based management, "where citizens and stakeholders are included in the management of resources" (Keough \& Blahna, 2006). Direct community involvement to support community agendas and involvement of community from the early stage is the core objective of most of the citizen science activities, and can take the form of contributory, collaborative, or co-created projects. On the other hand interactive PSS are generally implemented either in laboratory with participants playing certain roles or with real world stakeholders, usually professional experts, under close to real world situations or context, resulting into limited usage of PSS by general citizens.

PSS scholars, therefore, need to consider community engagement at the core of PSS usage by embedding the PSS into the community based research activities and the broader social context by which the scientific question are collaboratively asked. Having community involvement at its core, PSS can be tailor made to address community issues directly. This may also result in greater acceptance of PSS usage and application by the broader citizens as one of its strength. However, in order for PSS tools to get adopted more widely and by diverse participants, PSS scholars should also need to concentrate on motivational factors for PSS users. This is the weakness that is also generally faced by citizen science activities (Rotman et al., 2012). By engaging community directly together with relevant organizations and agencies as in the citizen science activities, opportunities to forge partnerships can be built. As cooperative relationships with 
influential organizations may increase citizen participant motivation and passion (Schmidthuber et al., 2019) that may ultimately help in developing communities of practice for interactive PSS usage and applications. Nonetheless, community engagement is usually time and resource intensive.

\subsection{Formats of engagement}

Different hackerspace, makerspace, DIY activities, living labs, gaming etc in recent years are forming alternative networks in knowledge production and sharing and ultimately trending as way of engaging citizens in many of the citizen science activities for pragmatic response to various urban challenges. These hackerspace, makerspace, DIY activities, living labs/fab labs act as intermediaries and translational sites offering unique opportunities for bridging the gaps between knowledge based on experts/scientists and the everyday interests, practices and problems of general citizen in diverse local contexts (Kera, 2012). Moreover, these spaces offer co-designing activities (Jiang et al., 2016) that can potentially help in addressing digital illiteracy among the users.

In the current situation, most of the interactive PSS tools and applications are developed by developers, usually in research environment, with little to none involvement of users, or if any only the professional experts. Similarly, these are usually implemented in traditional workshop format. In this respect, the above forms of engagement can potentially drive early involvement of citizens also in the interactive PSS development. This can result in the early identification of the requirement for the design of interactive PSS, so that as an opportunity the tools and technologies can be adapted to the needs of the users rather than adapting their needs to technological exigencies. Also, by identifying requirements in the design and development of interactive PSS tools, technology can be better fitted to the task to be fulfilled by such technology, increasing their chances of wide adoption. Similarly, innovative uses of technology, for instance in the form of alternate and augmented reality games, context-aware games, games involving social networking, may expedite team formation, improve participants' motivation, create a safer space to make their stake explicit. As a result citizen engagement is practiced through an open decision-making process, collaborative learning and knowledge exchange that happens in such spaces. In addition, early involvement in the development and usage of PSS application through such design spaces, may also create sense of ownership resulting into wider use and application of interactive PSS tools. Nonetheless, such engagement requires resources, time and space, which holds true to any kind of bottom-up processes and as one of the weaknesses. Thus, in order to embed interactive PSS development and applications with such form of engagement, great effort must be put into bringing coherence to the process, and overcome the weakness of lack of sufficient time, resources, and/or experience to allocate towards it. As for threat, while engaging broad citizens in co-design activities, tension may arise between the desire for simplicity and level of detail required to accomplish planning goals, when deciding how to represent complex real world issues in the interactive PSS tools.

\subsection{Technological development}

The speed at which new technologies are being emerged within scientific and citizen-science communities indicate that volunteers are more willing to adopt technology than ever before. In addition, open science movement in citizen science is redefining how the public engages with, and is engaged in science (Hecker et al., 2018). Open science engages with issues such as accessible data and publications, open evaluation and policies as well as developing its own tools. This includes open access, which is driven by the understanding that publicly funded research should be accessible to all members of society; sharing information and results for promotion of the open access publication model, establishing open data repositories, as well as developing open sourced tools and web platform. Technological development, such as the ubiquity of internet and mobile apps, open sourced software and web platforms, low cost of location devices, wireless sensor networks are driving forces in these regards. As a result, it is changing the way of involving citizen by opening up research throughout the process, from idea generation and planning to conducting the research and disseminating outputs. On the contrary, the technological development in interactive PSS shows that although the hardware solution is getting more and more advanced, but the software platform being used are usually off-the shelf software. This has resulted into less flexible tools and applications, which are not publicly available.

By leveraging the development of open source software, developers of interactive PSS can reduce the barriers being imposed by off-the shelf software and applications use in interactive PSS. Similarly, web-based platform, use of mobile applications can assist in the evolution of interactive PSS from its current format of same-place-same-time mode to differenttime-different-place or same-time-different-place mode, resulting into more flexibility in its usage and applications. The use of mobile based applications, web based platforms, particularly in initial stage of planning, may provide opportunities to enlarge information source through data accessibility and sharing possibility and to incorporate citizen generated data and perceptions in the planning and decision making. Similarly, integrating such aspects in interactive PSS applications, it may provide opportunities to expand the use and applications of PSS across multiple spatial, temporal and social scales. As such, it might help in overcoming the limitations of current interactive PSS - as an expert driven tools or as one time application. Nonetheless, there remains weakness of how to integrate such technological developments in the current form of interactive PSS. Similarly, data quality issues is inevitable and is worth discussing when users perform data generation (Crowston \& Prestopnik, 2013), so it is essential to verify data accuracy. Another weakness that is generally encountered when involving in digital communication is the privacy related issues (Drosatos et al., 2012). While using digital medium citizens' ignorance of personal privacy and potential risk of personal information expose can cause users or stakeholder confliction. The different interest of citizen is unavoidable that may lead to algorithmic discrimination, and diminish citizen safety. While involving broad citizen with diverse background, violating personal privacy may hinder in openly public expression and motivation to participate and may cause unintended consequences. Therefore, systematic privacy guard is essential while 
employing digital medium of engagement. Similarly, threat of the integration of such technology with the interactive PSS could be related to the loss of social learning and depersonalization of decision-making. Although virtual platform provide flexibility and possibility of involving large number of people, but it may also replace the face-to-face interaction, which is essential to engender social learning and collective decision making. Moreover, increasing the users of virtual platform, data contributors, does not necessarily mean that they are actively engaged in the decision making process.

\section{CONCLUSION}

Despite the huge potentials in engaging stakeholders in collaborative planning, interactive PSS are far from being standardized tools in practice and is still in the exploratory stage of growth when it comes to broader citizen engagement. On the same note, citizen science represents a new type of open movement, involving citizens in research activities in order to increase public understanding of science as well as bringing transformative potentials. As such, it seems likely that citizen science offers significant lessons on advancing interactive PSS for facilitating broader citizen engagement. Therefore, the goal of this research is to conduct the SWOT on integrating the aspects of citizen science activities with interactive PSS. In particular, we explored the three aspects in the domain of citizen science activities-forms of research, formats of engagement and technological development-in order to derive the strengths, weaknesses, opportunities, and threats of integrating these aspects in interactive PSS.

In general, we can conclude that in order to advance the interactive PSS towards broader citizen engagement, PSS scholars need to begin by changing the way research and operationalization of interactive PSS is being carried out in the present context. It needs to change from lab-based experiments or with few number of stakeholders working around the table in one time application into a long-standing activity embedded in community based-research and broader social context. Secondly, interactive PSS can benefit from different forms of intermediaries spaces such as hackerspace, makerspace, living labs/fablabs, in order to drive early involvement of citizens, for creating shared ownership of the tools through co-designing, thereby increase the acceptance. Thirdly, open science movement in citizen science domain and the availability of enabling technologies such as mobile based applications, webplatforms, gaming in variety of citizen science projects can offer huge potentials for interactive PSS to enlarge the information sources and incorporate citizens' perceptions.

\section{REFERENCES}

Al-Kodmany, K., 2001. Bridging the gap between technical and local knowledge: Tools for promoting community-based planning and design. Journal of Architectural and Planning research, 110-130.

Arciniegas, G., Janssen, R., \& Rietveld, P., 2013. Effectiveness of collaborative map-based decision support tools: Results of an experiment. Environmental modelling \& software, 39, 159-175.

Bonney, R., Ballard, H., Jordan, R., McCallie, E., Phillips, T., Shirk, J., \& Wilderman, C. C., 2009. Public Participation in
Scientific Research: Defining the Field and Assessing Its Potential for Informal Science Education. A CAISE Inquiry Group Report. Online Submission.

Brail, R. K., \& Klosterman, R. E., 2001. Planning support systems: Integrating geographic information systems, models, and visualization tools: ESRI, Inc.

Brossard, D., Lewenstein, B., \& Bonney, R., 2005. Scientific knowledge and attitude change: The impact of a citizen science project. International Journal of Science Education, 27(9), $1099-1121$.

Burke, E. M., 1979. A participatory approach to urban planning: Human Sciences Pr.

Clery, D. 2011. Galaxy Zoo volunteers share pain and glory of research: American Association for the Advancement of Science.

Cohn, J. P., 2008. Citizen science: Can volunteers do real research? BioScience, 58(3), 192-197.

CommunityViz Scenario 360. Available online. Retrieved from explained.com/communityviz/scenario360.html http://communityviz.city-

Conrad, C. C., \& Hilchey, K. G., 2011. A review of citizen science and community-based environmental monitoring: issues and opportunities. Environmental monitoring and assessment, 176(1-4), 273-291.

Crowston, K., \& Prestopnik, N. R., 2013. Motivation and data quality in a citizen science game: A design science evaluation. Paper presented at the 2013 46th Hawaii International Conference on System Sciences.

Danielsen, F., Burgess, N. D., Jensen, P. M., \& Pirhofer-Walzl, K., 2010. Environmental monitoring: the scale and speed of implementation varies according to the degree of peoples involvement. Journal of Applied Ecology, 47(6), 11661168 .

Densham, P. J., \& Goodchild, M. F., 1989. Spatial decision support systems: A research agenda. Unknown Journal, 707716.

Döweling, S., Tahiri, T., Riemann, J., \& Mühlhäuser, M., 2016. Collaborative Interaction with Geospatial Data-A Comparison of Paper Maps, Desktop GIS and Interactive Tabletops Collaboration Meets Interactive Spaces (pp. 319348): Springer.

Drosatos, G., Efraimidis, P. S., Athanasiadis, I. N., D'Hondt, E., \& Stevens, M., 2012. A privacy-preserving cloud computing system for creating participatory noise maps. Paper presented at the 2012 IEEE 36th Annual Computer Software and Applications Conference.

Flacke, J., \& De Boer, C., 2017. An interactive planning support tool for addressing social acceptance of renewable energy projects in the Netherlands. ISPRS international journal of geo-information, 6(10), 313. 
Flacke, J., Shrestha, R., \& Aguilar, R., 2019. Strengthening Participation using Interactive Planning Support Systems: A Systematic Review. ISPRS international journal of geoinformation, under submission.

Forester, J., 1993. Critical theory, public policy, and planning practice: SUNY Press.

Geertman, S., \& Stillwell, J., 2012. Planning support systems in practice: Springer Science \& Business Media.

Healey, P., 1996. The communicative turn in planning theory and its implications for spatial strategy formation. Environment and Planning B: Planning and design, 23(2), 217-234.

Hecker, S., Haklay, M., Bowser, A., Makuch, Z., \& Vogel, J., 2018. Citizen science: innovation in open science, society and policy: UCL Press.

Jankowski, P., Nyerges, T. L., Smith, A., Moore, T., \& Horvath, E., 1997. Spatial group choice: a SDSS tool for collaborative spatial decisionmaking. International journal of geographical information science, 11(6), 577-602.

Jankowski, P., Robischon, S., Tuthill, D., Nyerges, T., \& Ramsey, K., 2006. Design considerations and evaluation of a collaborative, spatio-temporal decision support system. Transactions in GIS, 10(3), 335-354.

Jiang, Q., Kresin, F., Bregt, A. K., Kooistra, L., Pareschi, E., Van Putten, E., Volten, H., \& Wesseling, J., 2016. Citizen sensing for improved urban environmental monitoring. Journal of Sensors, 2016.

Keenan, P. B., \& Jankowski, P., 2019. Spatial decision support systems: three decades on. Decision Support Systems, 116, 6476.

Keough, H. L., \& Blahna, D. J., 2006. Achieving integrative, collaborative ecosystem management. Conservation Biology, 20(5), 1373-1382.

Kera, D., 2012. Hackerspaces and DIYbio in Asia: connecting science and community with open data, kits and protocols. Journal of Peer Production, 2(Jun), 1-8.

Kimura, A. H., \& Kinchy, A., 2016. Citizen science: Probing the virtues and contexts of participatory research. Engaging Science, Technology, and Society, 2, 331-361.

Klosterman, R. E., 1997. Planning support systems: a new perspective on computer-aided planning. Journal of Planning education and research, 17(1), 45-54.

Pelzer, P., Arciniegas, G., Geertman, S., \& de Kroes, J., 2013. Using MapTable ${ }^{\circledR}$ to learn about sustainable urban development Planning support systems for sustainable urban development (pp. 167-186): Springer.

Pelzer, P., Geertman, S., van der Heijden, R., \& Rouwette, E., 2014. The added value of Planning Support Systems: A practitioner's perspective. Computers, Environment and Urban Systems, 48, 16-27.
Rotman, D., Preece, J., Hammock, J., Procita, K., Hansen, D., Parr, C., Lewis, D., \& Jacobs, D., 2012. Dynamic changes in motivation in collaborative citizen-science projects. Paper presented at the Proceedings of the ACM 2012 conference on computer supported cooperative work.

Schmidthuber, L., Piller, F., Bogers, M., \& Hilgers, D., 2019. Citizen participation in public administration: investigating open government for social innovation. $R \& D$ Management, 49(3), 343-355.

Shrestha, R., Köckler, H., Flacke, J., Martinez, J., \& Van Maarseveen, M., 2017. Interactive knowledge co-production and integration for healthy urban development. Sustainability, 9(11), 1945.

Silvertown, J., 2009. A new dawn for citizen science. Trends in ecology \& evolution, 24(9), 467-471.

Sîrbu, A., Becker, M., Caminiti, S., De Baets, B., Elen, B., Francis, L., Gravino, P., Hotho, A., Ingarra, S., \& Loreto, V., 2015. Participatory patterns in an international air quality monitoring initiative. PLOS one, 10(8), e0136763.

Snik, F., Heikamp, S., de Boer, J., Keller, C., van Harten, G., Smit, J., Rietjens, J., Hasekamp, O., Stam, D., \& Volten, H., 2012. iSPEX: The creation of an aerosol sensor network of smartphone spectropolarimeters. Paper presented at the EGU General Assembly Conference Abstracts.

Sugumaran, R., \& Degroote, J., 2010. Spatial decision support systems: principles and practices: Crc Press.

te Brömmelstroet, M., 2017. PSS are more user-friendly, but are they also increasingly useful? Transportation Research Part A: Policy and Practice, 104, 96-107.

Turoff, M., Hiltz, S. R., Bahgat, A. N., \& Rana, A. R., 1993. Distributed group support systems. MIS quarterly, 17(4), 399417.

Van Brussel, S., \& Huyse, H., 2019. Citizen science on speed? Realising the triple objective of scientific rigour, policy influence and deep citizen engagement in a large-scale citizen science project on ambient air quality in Antwerp. Journal of Environmental Planning and Management, 62(3), 534-551.

Vonk, G., Geertman, S., \& Schot, P., 2005. Bottlenecks Blocking Widespread Usage of Planning Support Systems. Environment and Planning A: Economy and Space, 37(5), 909924. doi:10.1068/a3712

Vonk, G., \& Ligtenberg, A., 2010. Socio-technical PSS development to improve functionality and usability - Sketch planning using a Maptable. Landscape and Urban Planning, 94(3-4), 166-174.

Walsh, M. L., 1997. Building citizen involvement. International City/County Management Association, Washington, DC.

Whitelaw, G., Vaughan, H., Craig, B., \& Atkinson, D., 2003. Establishing the Canadian community monitoring network. Environmental monitoring and assessment, 88(1-3), 409-418. 
Wiggins, A., \& Crowston, K., 2011. From conservation to crowdsourcing: A typology of citizen science. Paper presented at the 2011 44th Hawaii international conference on system sciences.

Willett, W., Aoki, P., Kumar, N., Subramanian, S., \& Woodruff, A., 2010. Common sense community: scaffolding mobile sensing and analysis for novice users. Paper presented at the International Conference on Pervasive Computing. 